\title{
Article \\ Estimation of Total Solar Transmittance for Twin-Wall Polycarbonate Sheet with Rectangular Structure on the Basis of Experimental Research
}

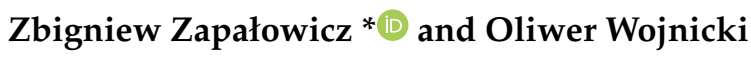

check for

updates

Citation: Zapałowicz, Z.; Wojnicki, O.

Estimation of Total Solar Transmittance for Twin-Wall Polycarbonate Sheet with Rectangular Structure on the Basis of Experimental Research. Energies 2022, 15, 1360. https:// doi.org/10.3390/en15041360

Academic Editors: Dawid Taler, Magdalena Jaremkiewicz and Chi-Ming Lai

Received: 27 January 2022

Accepted: 11 February 2022

Published: 14 February 2022

Publisher's Note: MDPI stays neutral with regard to jurisdictional claims in published maps and institutional affiliations.

Copyright: (c) 2022 by the authors. Licensee MDPI, Basel, Switzerland. This article is an open access article distributed under the terms and conditions of the Creative Commons Attribution (CC BY) license (https:// creativecommons.org/licenses/by/ $4.0 /)$.
Department of Energy Technologies, Faculty of Mechanical Engineering and Mechatronics, West Pomeranian University of Technology, Szczecin, al. Piastów 17, 70-310 Szczecin, Poland; oliwer.wojnicki@gmail.com

* Correspondence: zbigniew.zapalowicz@zut.edu.pl

\begin{abstract}
The consumption of heat energy as well as electric power in an exploitation process of a building construction depends among others on properties of materials applied to construct its partitions. Increasingly, glass is being replaced by plastics in transparent partitions, including multiwall polycarbonate sheets. Light transmission and solar radiation transferred to the object's inside through transparent partitions are decisive factors for its lighting and energy balance. The present paper presents an analysis, on an experimental basis, of the changes of total solar transmittance (TST) for a clear twin-wall polycarbonate sheet with a rectangular structure applied as a swimming pool enclosure. Research shows that values of the above parameter do not depend meaningfully on cloudiness but on time of day. Values of TST can change in the daytime depending on incidence angles and on shares of direct and diffusive solar radiation in global solar radiation. TST values are in the range $0.6-0.7$, and they are lower than the value of 0.8 , which is given by the producer in the product card.
\end{abstract}

Keywords: total solar transmittance; polycarbonate transmittance; polycarbonate enclosure; polycarbonate twin-wall structure

\section{Introduction}

Efficient energy consumption is one of the strategic targets for the economic development of the modern world [1]. One of the more important economic branches is the constructing industry. The exploitation of objects requires that both power and heat energy are supplied [2]. Both kinds of energy are consumed most of all for heating and/or air conditioning (ventilation) buildings. The consumption ratio for these two kinds of energy changes depending on the climate zone, on applied heating installation, and/or applied air conditioning. On the other hand, thermal gains and losses in constructions are essential for energy consumption by the mentioned installations. Thus, the properties of building materials used for partitions can decisively affect the heat fluxes exchanged between the environment and a building's inside.

For the reason of a building's energy balance, the construction of transparent building partitions is essentially important. Light and energy transmission through transparent partitions was and remains the investigation target for a great number of researchers. Control over the access of solar light and energy to the object is a strong motivation for such investigations. They most often concern the transmission of solar radiation through glass or transparent constructions made up from several sheets of glass with spaces between them filled in with air or noble gas with low total pressure. In glass constructions, layers of individual transparent materials are parallel to each other, and solar beams are refracted only in boundary areas of respective media. Then, the inclination angle of solar radiation on the glass surface and its inclination and orientation to the sun are significant parameters. 
The transmission of solar radiation through such partitions was analysed, among others, by Karlsson and Ross [3], Karlsson et al. [4], Song and Haberl [5], and Kralj et al. [6].

Another meaningful problem of the modern construction industry is the excess of energy transmitted to the building's interior when solar radiation is too intensive. For this reason, transparent partitions are implemented with shading systems. Processes of solar transmission through such partitions were analysed, among others, by Manz [7], Simmler, and Bidner [8]. In the newest constructions of building partitions, granular aerogel can be placed between the glass sheets. It reduces the temperatures gradient between the object's interior and environment on a sunny day. Research on heat and energy transmission for windows made with this technology was carried on by Moretti et al. [9]. Transmittance control of glass partitions is possible in case of glass partitions built with the application of polymer dispersed liquid crystal (PDLC). When voltage is applied to such a material, its transmittance can change. The effect of sky clearness index on the transmittance of a glass partition with PDLC was investigated, among others, by Ghosh et al. [10].

In turn, research on heat loss and the weakening of light transmission for a transparent partition made of a double-walled polycarbonate plate filled with granulated aerogel was carried out by Dawson et al. [11]. Their study shows that this technical solution of the building partition reduces the heat loss of the building by about $80 \%$, without changing the light transmission.

However, increasingly, more building partitions are made of plastic (e.g., polycarbonate sheets, polyethylene sheets). Plastic is applied to build transparent partitions, among others, enclosures for swimming pools, partitions for sports stadiums, greenhouses, etc. [12-18].

Polycarbonate sheets belong to popular materials [19] that can substitute glass sheets. Polycarbonate is a polymer belonging to the group of carboxylic acid polyesters [12,20]. Producers offer a wide variety of ready-made sheets made of polycarbonate, which are applied in the construction industry [12-17]. The sheets may be of solid or multi-wall structure (Figure 1).

a)

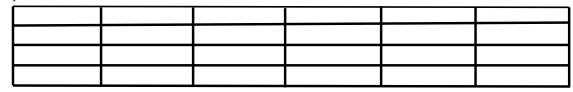

c)

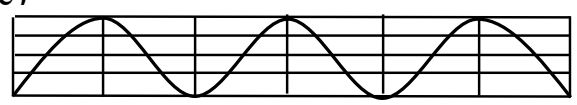

b)

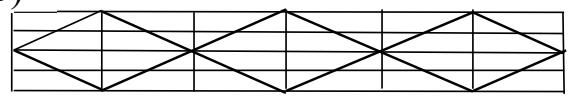

Figure 1. Types of multi-wall polycarbonate sheets: (a) rectangular structure, (b) truss structure, (c) structure with internal sine wave.

In case of transparent building partitions made of polycarbonate sheets, the process of solar transmission can be quite complicated, particularly when their structure is not homogenous. Additionally, such polycarbonate sheets are connected with each other by ribs being their integral parts which, in turn, causes processes of solar refraction and reflection of complex character [21].

For practical purposes, the optical properties of polycarbonate sheets are meaningful as they are decisive for the amount of transmitted light and for energy transferred to the object. Optical properties of sheets offered for sale are estimated in lab conditions, according to European standard EU [22]. The data are given by the producer on the product card. A question arises as to whether the values of optical parameters given in catalogues are kept in exploitation conditions for polycarbonate sheets. The question is most important by modelling of heat exchange processes through such partitions (e.g., through the encloser of swimming pools $[23,24])$. One of the more important parameters for the process of solar transmission through transparent partition is total solar transmittance (TST) [21].

Research on TST for several polycarbonate sheets that differed in structures was carried on by Čekon et al. [25-27]. On the basis of yearly research, Čekon gave in the 
paper [25] relations between TST and global solar radiation as well as between TST and irradiance incidence angle. He stated that TST increased with the growth of global solar radiation and diminished with angle of incidence.

The aim of the present paper was the determination of TST for a chosen clear twinwall polycarbonate sheet with a rectangular structure in real conditions. It should be investigated whether the values of experimental results are related to values obtained in lab conditions. The important questions address the relation between values of TST obtained in lab conditions and values obtained in experimental research, whether they are the same, and if the clearness index has an effect on TST.

\section{Materials and Methods}

\subsection{Parameters Solar Energy Transmission}

Figure 2 shows schematically the phenomenon of solar energy transmission through a multi-wall polycarbonate sheet, which can be treated as a transparent solid body. Incident solar radiation $(\mathrm{A})$ on the front wall of a polycarbonate sheet is partially reflected (B) and transmitted through the sheet's material (C). In turn, part of the solar radiation in the sheet's material is refracted, and then, it is transmitted to the inside of the object as direct solar transmission (F). A small amount of transmitted solar radiation is absorbed $\mathrm{E}$ by polycarbonate. If the sheet's structure is more complex, further solar radiation reflections and refractions may occur, as it is shown in Figure 1. Furthermore, the front and back walls of the sheet emit energy accumulated in polycarbonate to the environment (D) and to the object's inside (F). Parameter TST (H) is the sum of direct solar transmission (F) and energy emitted from the back wall of the polycarbonate sheet $(\mathrm{G})$.

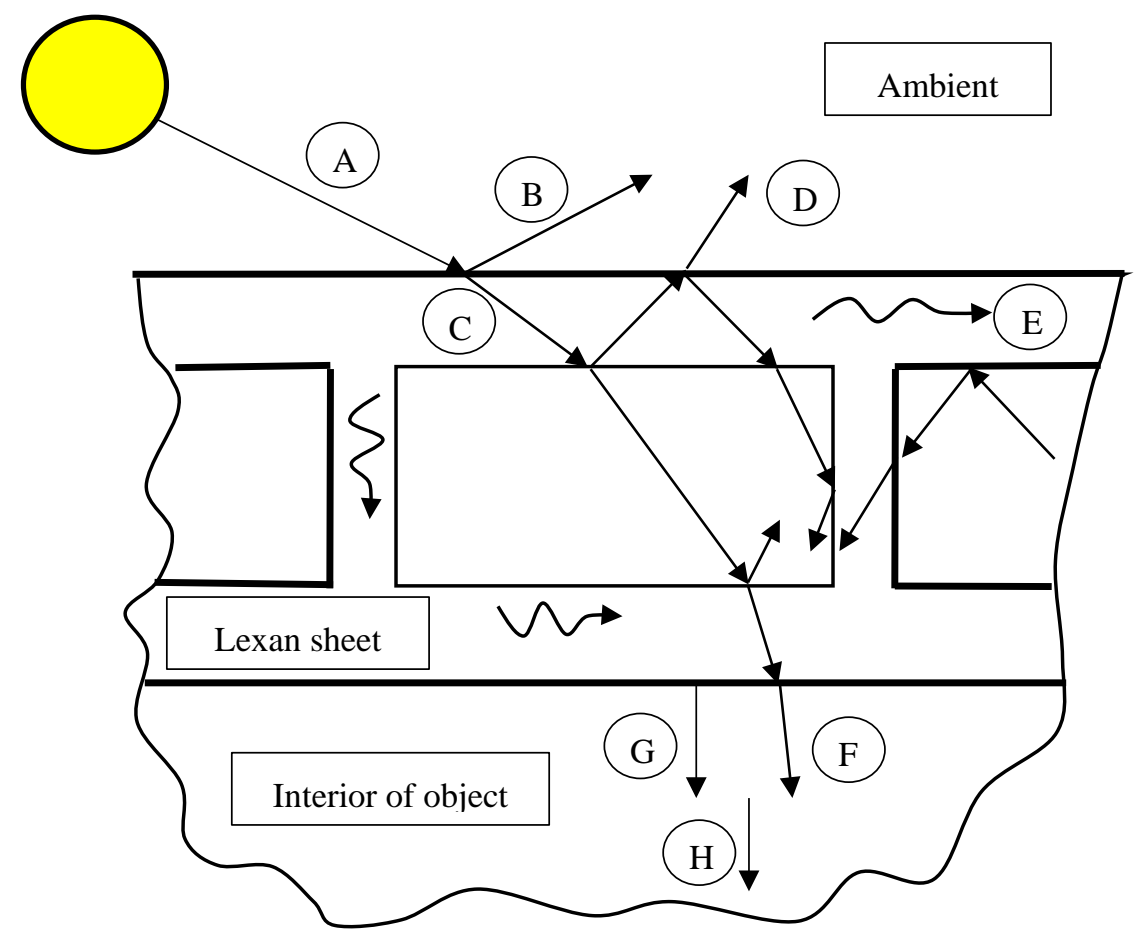

Figure 2. Scheme of solar transmission through a multi-wall polycarbonate sheet.

As it has already been mentioned, from a practical point of view, amounts of light and energy released to the object's inside are relevant information. That is why producers of polycarbonate sheets give generally three parameters that characterize the optical properties of enclosures in their catalogues [12-17]:

- $\quad$ Light transmission (LT);

- Direct solar transmission (DT);

- Total solar transmittance (TST). 
The above parameters are determined in laboratory conditions [22].

\subsection{Test Stand}

Experimental research was carried out on the test stand built on the roof of the Department of Energy Technologies, West Pomeranian University of Technology, Szczecin. Figure 3 shows the view of the test stand.

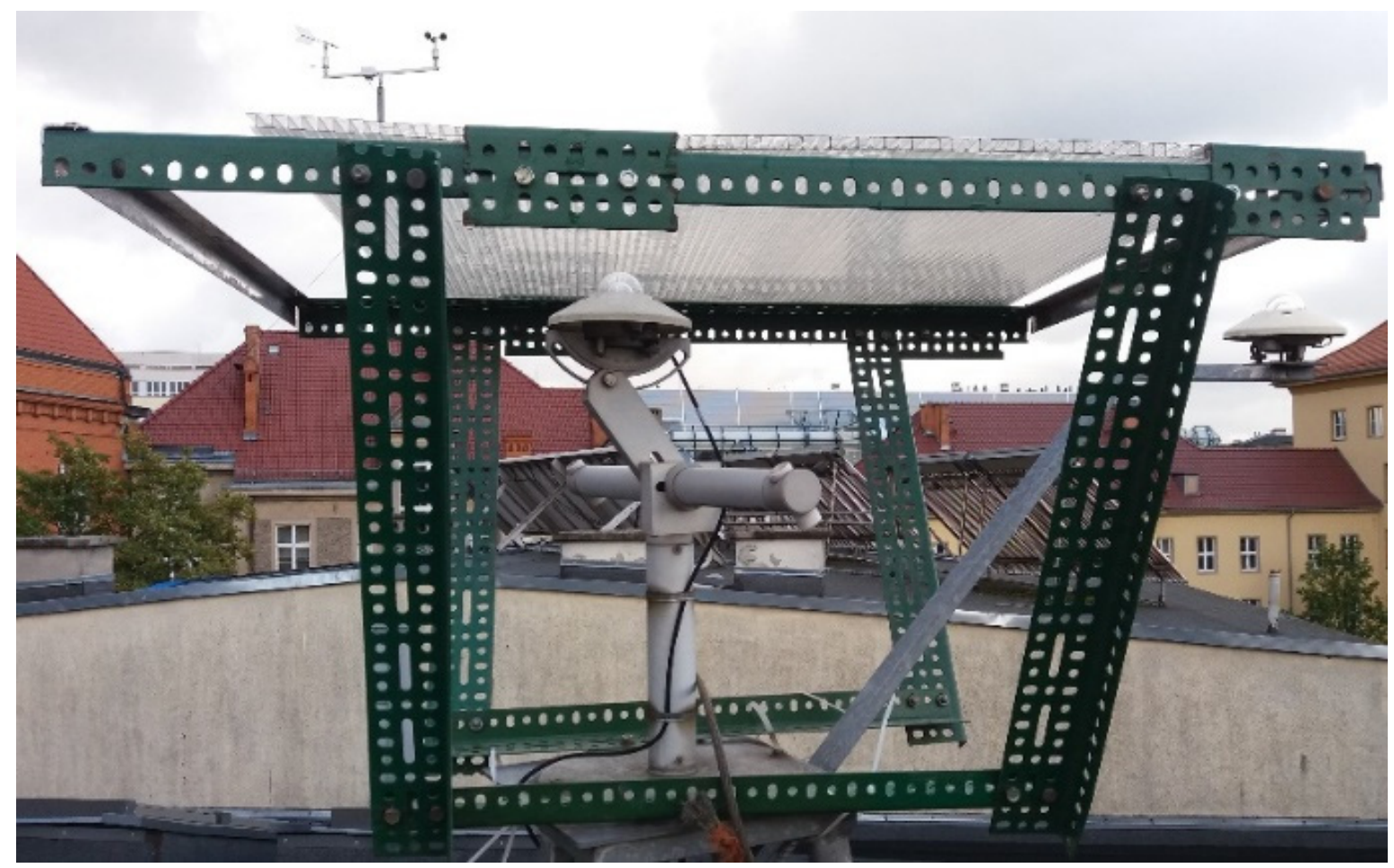

Figure 3. View of test stand (photo: Zbigniew Zapałowicz).

A clear twin-wall polycarbonate sheet with a rectangular structure produced by Sabic, catalogue-signed as LT2UV102RS17 [28,29], was chosen for the research. The sheet is commonly applied as a swimming pool enclosure. The sheet was made of resin with trademark Lexan. Its TST was 0.8 and LT was 0.81 , whereas its DT was 0.76 . The height and width of the single sheet's cell was $0.010 \mathrm{~m}$, respectively. The sheet was attached to a metal frame, which was then placed on a stand. The axes of the channels of the polycarbonate sheet are perpendicular to the $\mathrm{N}-\mathrm{S}$ direction.

In order to measure total irradiance, two Kipp \& Zonen pyranometers [30] with sensors of type CMP-11 were applied. They were connected with a data acquisition unit. One of them was placed under the sheet, and the latter one was placed near the sheet. The sensors measured irradiance above $\left(G_{1}\right)$ and beneath the polycarbonate sheet $\left(G_{2}\right)$.

\subsection{Methodology of Research}

Irradiances $\left(G_{1}, G_{2}\right)$ measured by means of pyranometers were registered every $20 \mathrm{~min}$. The TST for the polycarbonate sheet under research was calculated from the relation:

$$
\mathrm{TST}=G_{2} / G_{1} .
$$

The same methodology of TST measurements was applied, among others, by Tantau et al. [18], Song and Haberl [5], and Čekon et al. [25-27]. However, they applied test stands that differed by construction and by implementation from the stand applied in the present paper.

The location of the test stand and lack of side protection for pyranometers caused that irradiance reflected from neighbouring objects could affect both sensors. That is why it was 
assumed that the measured values of irradiance above and beneath the sheet included the component of reflected irradiance.

Incident radiation on the surface of the polycarbonate sheet depends on the weather conditions and atmospheric condition in the location of the test stand. In order to estimate how cloudiness affects TST through the polycarbonate enclosure, a temporal sky clearness index $(\mathrm{K})$ [31] was introduced in the analysis. In the present paper, this index is defined as a ratio of respective irradiances above the polycarbonate sheet $\left(G_{1}\right)$ and on the surface of the outer atmospheric layer $\left(G_{0}\right)$ :

$$
K=G_{1} / G_{0} .
$$

Extra-terrestrial solar radiation $\left(G_{0}\right)$ was calculated from the relation:

$$
G_{0}=G_{s}\left(1+0,033 \cos \frac{360 n}{365}\right)(\cos \Phi \cos \delta \cos \omega+\sin \Phi \sin \delta) K
$$

Parameter $G_{S}=1367 \mathrm{~W} / \mathrm{m}^{2}$ in Equation (3) denotes the solar constant, $\mathrm{n}$ is the subsequent day of the year, and angle $\Phi$ is latitude $\left(\Phi\right.$ for Szczecin $\left.=53.403^{\circ} \mathrm{N}\right)$. Solar declination $\delta$ depends on the season of the year and can be calculated from the following equation:

$$
\delta=23,34 \sin \left(360 \frac{284+n}{365}\right) .
$$

Then, the hour angle depends on the true solar time, and its value is calculated from the relation:

$$
\omega=15 \cdot(\tau-12,00) .
$$

Measurements were made for local time $\tau_{z o n e}$, so time correction is necessary, according to equation:

$$
\tau=\tau_{\text {zone }}+4\left(L_{\text {zone }}-L_{l o c}\right)+E .
$$

where $L_{z o n e}, L_{l o c}$-are lengths of standard meridian $\left(L_{z o n e}=15^{\circ} \mathrm{E}\right)$ and local meridian (for Szczecin $L_{l o c}=14.529^{\circ} \mathrm{E}$ ), respectively, and $E$ is the equation of time.

In addition, a systematic error between the time registered by the data acquisition system and local time was considered in the calculations.

It should be pointed out that the calculated value of the temporal atmosphere clearness index is of approximate character because irradiance above the polycarbonate sheet considers also reflected irradiance.

\section{Results}

Research was carried out in summer 2020. The present paper presents only research results obtained in August. Detailed elaboration of the research results for this month is given in paper [32]. Measurement results for irradiance values higher than $1000 \mathrm{~W} / \mathrm{m}^{2}$ were neglected in research analysis, as they were considered to be gross errors.

For each day under research, diagrams of irradiance changes out of the earth's atmosphere, as well as above and beneath the polycarbonate sheet, as a function of time were drawn. In addition, for each day under research, diagrams of parameters TST and K as a function of time, as well as relation between TST and K were drawn. For example, the figures in in Appendix A show runs of changes for analysed parameters only for the chosen examples of days of August that are characterised by different cloudiness.

Figures 4-7 present collective research results for the month under analysis. Figure 4 shows TST parameter values as a function of irradiance $G_{1}$ reaching a polycarbonate sheet. For low values of irradiance (up to $100 \mathrm{~W} / \mathrm{m}^{2}$ ), parameter TST diminishes with the increase in $G_{1}$. For irradiance $G_{1}$ in the range of about 100 to $700 \mathrm{~W} / \mathrm{m}^{2}$, parameter TST shows significant changeability. It can only be stated that with the growth of irradiance $G_{1}$ for this range, values of parameter TST aim at the value of 0.7 . For values of irradiance higher than $700 \mathrm{~W} / \mathrm{m}^{2}$, parameter TST has values close to 0.7 . In addition, it can be stated that if irradiance $G_{1}$ aims at zero, then parameter TST approaches the value 0.9 . An increase 
in the transmissivity of the sheet can be caused by the fact that solar beams directly reach the pyranometer's sensor beneath the sheet with no contact to the sheet. This situation can occur by very small values of altitude angles.

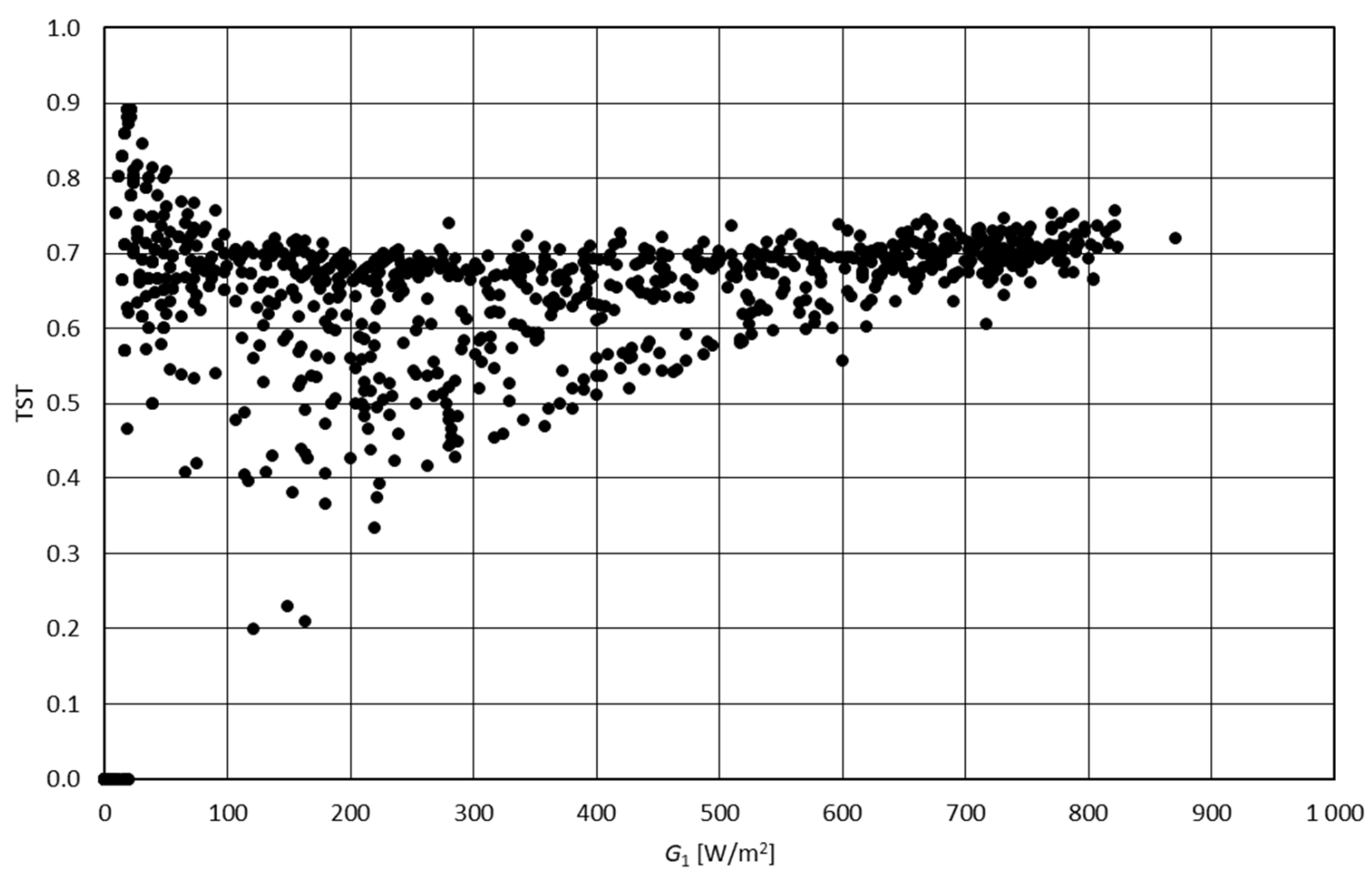

Figure 4. Parameter TST vs. $G_{1}$.

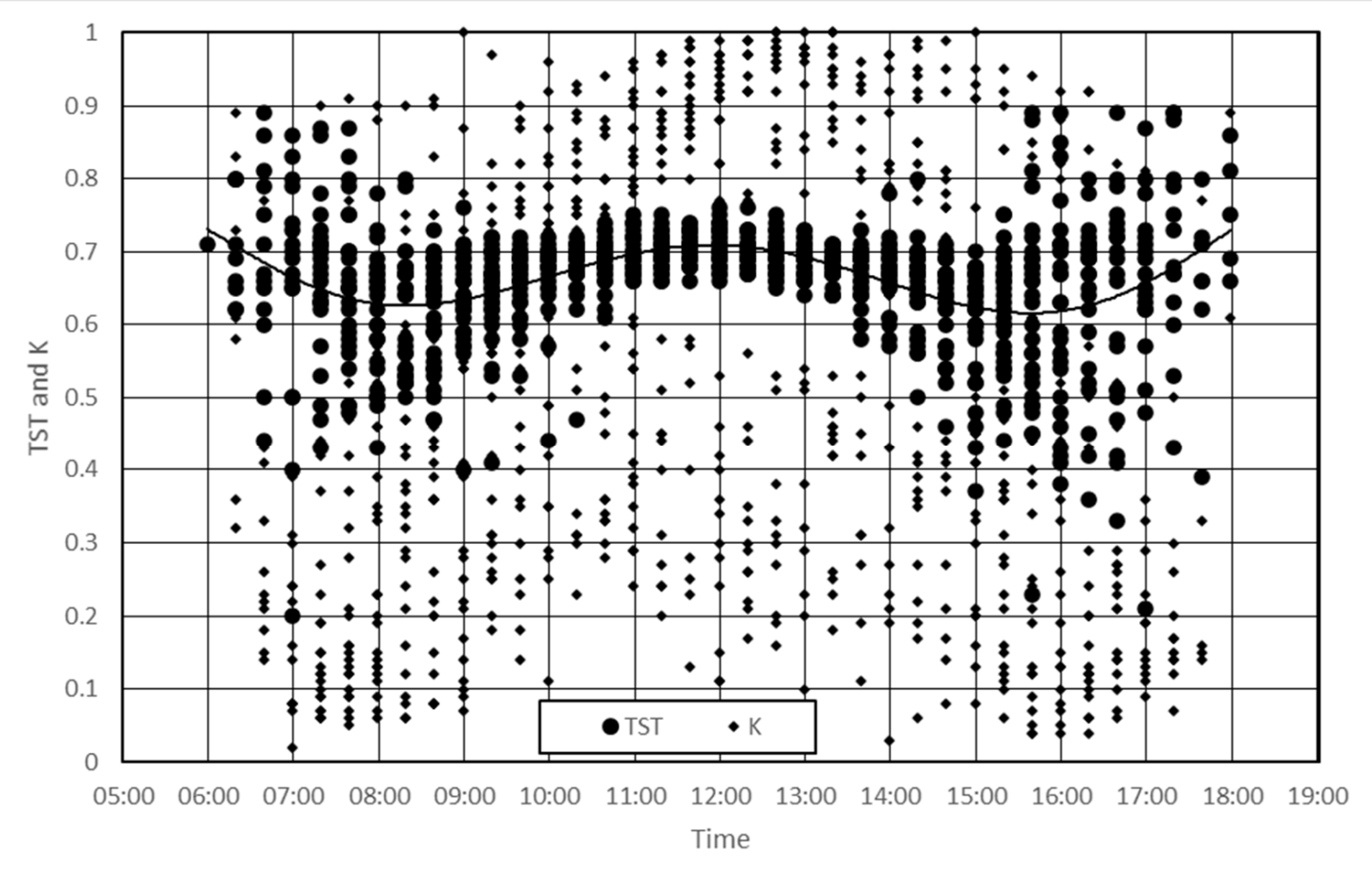

Figure 5. Parameters TST and K vs. time. 


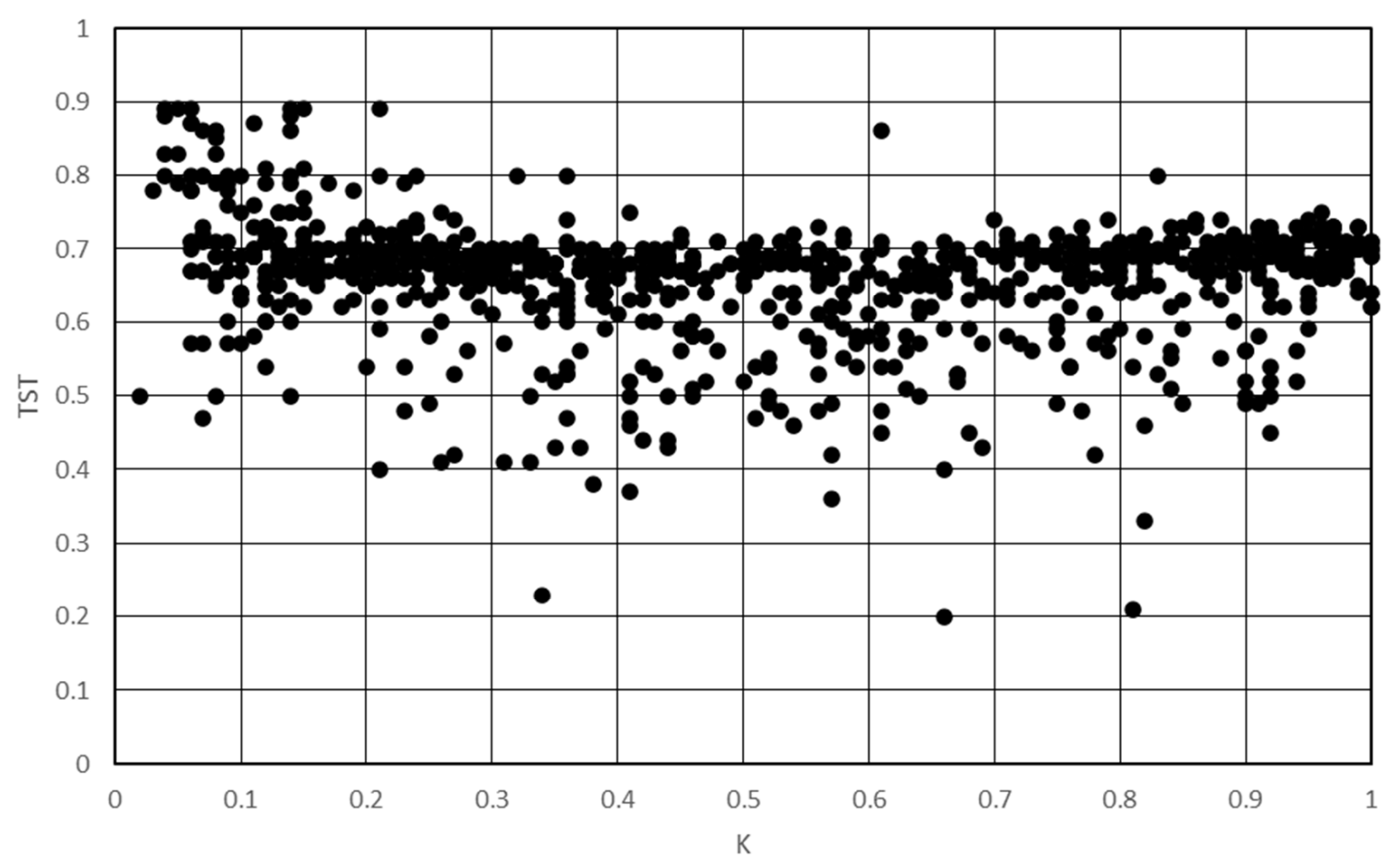

Figure 6. Parameter TST vs. K.

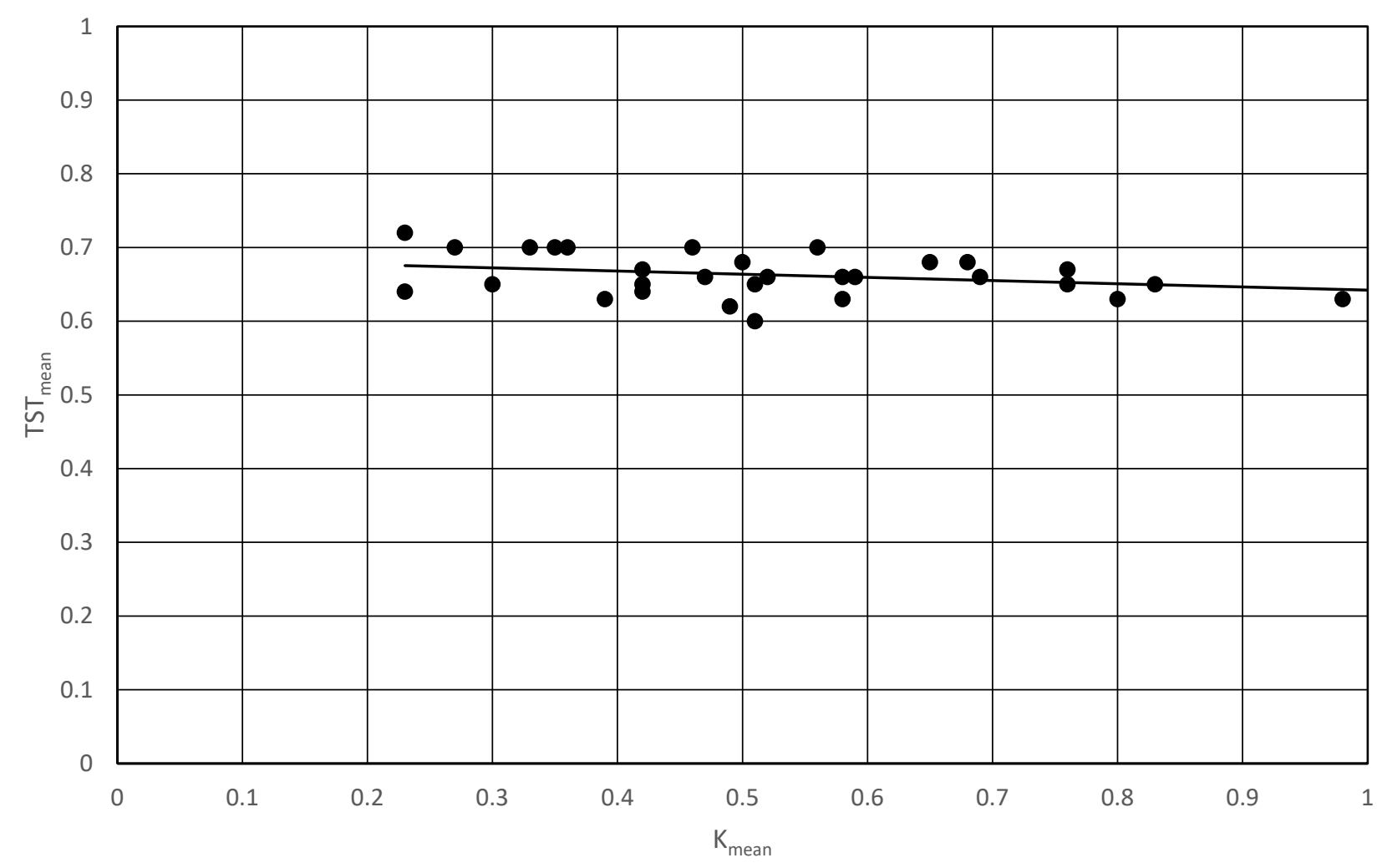

Figure 7. Parameter $\mathrm{T}_{\text {mean }}$ vs. $\mathrm{K}_{\text {mean }}$. 
Thus, the present research confirms conclusions made by Čekon and Slávik in paper [25]. They stated that for similar clear twin-wall polycarbonate sheets with rectangular structures that are vertical southeast (SE) oriented, measured values of TST equalled 0.74 and 0.63 . The first value received by Čekon and Slávik was measured by means of procedures ASTM G 173 [26], and the second one was obtained according to procedures ASTM E1084-86 [25]. In their research, the declared TST for the investigated polycarbonate sheet is 0.82 .

Čekon and Slávik developed a linear approximation equation for a vertically positioned polycarbonate sheet $0.010 \mathrm{~m}$ thick but connected to a prismatic glass layer, which has the form TST $=0.55+7 \times 10^{-5} G_{1 p}$. This equation is valid for data of August when vertical solar irradiance $G_{1 p}$ is greater than $60 \mathrm{~W} / \mathrm{m}^{2}$. For such a sheet, in the paper [25], there are also given approximation equations making the parameter TST dependent on the radiation intensity $G_{1 \mathrm{p}}$ and on the incidence angle of sun- $\alpha$ (incidence angle of sun): TST $=0.5377+6.5 \times 10^{-5} G_{1 \mathrm{p}}$ and TST $=0.6146-1.5 \times 10^{-3} \alpha$, which are valid for the second half year after 1st June. Čekon and Slávik emphasise that the developed equations are only approximate, and they approximate the research results as a point cloud. However, these equations cannot be applied to compare the research results in this article due to different research conditions.

In turn, Tantau et al. [18] give a TST value of 0.6 after 5 years of operation of the clear twin-wall polycarbonate sheets with rectangular structures installed in the greenhouse roof. This value is slightly lower than the TNT value of 0.62 measured under laboratory conditions for a new, vertically oriented polycarbonate sheet.

Figure 5 presents all non-zero values of parameter TST as a function of parameter $\mathrm{K}$ for all measurements performed. It should be noted that for reasons given previously, parameter K defines only qualitatively the degree of cloudiness of the sky. In spite of significant changes in cloudiness, values of TST show some regular shape. If the run of trend is drawn, which is a polynomial of the 6th degree, it can be stated that the values of TST equal approximately 0.7 in early morning hours, in noon hours, and in late evening hours. On the other hand, values of TST are lower by noon and in the afternoon, and they equal approximately 0.6 .

Two reasons for such changeability of TST parameter can be defined. Firstly, shares of direct and diffusive solar radiation in global solar radiation change. Secondly, inclination angles of direct radiation change in time. In early day hours and late afternoon hours, the share of direct solar radiation in the total solar radiation is negligible (see Appendix A-Figure A4). Then, diffusive radiation is dominant. Direct solar radiation, incident at small angles, transmits through structures of the polycarbonate sheet and is refracted from the outside and inside walls of the sheet and from the ribs. When diffusive radiation begins to occur, its incident angles differ from each other, which causes their travel paths through the material to be more diversified and longer, which in turn causes bigger energy losses and a value decrease in parameter TST.

In consecutive morning hours, on clear or slightly cloudy days, the share of direct radiation in the global radiation grows, but the global radiation intensity is increasingly high. This phenomenon can cause that, in spite of the growing effect of diffusive radiation, a higher amount of energy is transmitted by direct radiation. In addition, direct radiation begins to incline at bigger angles, and it does not reflect from the ribs, but it only refracts in the bottom and top planes of the polycarbonate sheet. Thus, the increase in parameter TST is to be observed in the morning hours. A maximal value of parameter TST is achieved at the noon hours. In afternoon time, the changes tendency of parameter TST is similar to the changes of TST in the morning.

The studies of Tantau et al. [18] and Song and Haberl [5] confirm that the diffusion and direct solar radiation penetration through a plastic transparent partition is determined by the incidence angle of direct rays. This angle depends on the season, time of day, orientation of the object, and slope of the partition. 
Analysis of the distribution of points in the run in Figure 6 allows us to make similar observations as above. For the whole range of changes of parameter K, TST remains most of all in the range of $0.6-0.7$. Thus, the research results show that sky cloudiness affects meaningfully the transmissivity of a polycarbonate enclosure. It is advised to check if differences of values of TST can be caused by share proportions between direct and diffusive solar radiation in the global solar radiation.

Figure 7 shows changes of the mean twenty-four hours total solar transmittance as a function of the direct twenty-four hours atmosphere clearness index for each day. If research results are interpolated by a straight line, it can be observed that the value of parameter $\mathrm{TST}_{\text {mean }}$ diminishes with the growth of cloudiness. However, the observed correlation between parameters TST and $\mathrm{K}$ is advised to be confirmed.

Values of TST, determined by research, are lower than the value of the parameter given in the catalogue, and they equal about 0.8 [12-17].

\section{Conclusions}

The paper presents the results of an experimental study on the process of solar radiation transmission through a horizontally laid polycarbonate sheet with a rectangular structure. On the basis of analysis of obtained results for TST, it is stated that the values of the parameter TST obtained in the experimental research are mostly in the range 0.6-0.7, and they are lower than the value of 0.8 given by the producer in the product card. The results indicate that sky cloudiness has no relevant effect on the parameter TST. Values of the parameter TST obtained in early morning hours and in late evening hours, as well as at noon, are higher than the ones obtained for the remaining times of day. The changes of TST are caused by changes of solar radiation incidence in time and by changing values of direct and diffused radiation. It should be further investigated if shares of direct and diffusive solar radiation in global solar radiation can affect values of the parameter TST. The parameter TST increases with the growth of irradiance, if irradiance in the range lower than $100 \mathrm{~W} / \mathrm{m}^{2}$ is neglected.

Author Contributions: Conceptualization, Z.Z.; methodology, O.W.; investigation, O.W.; data analysis, Z.Z. and O.W.; writing-original draft preparation, O.W. and Z.Z.; writing-review and editing, Z.Z. All authors have read and agreed to the published version of the manuscript.

Funding: This research received no external funding.

Institutional Review Board Statement: Not applicable.

Informed Consent Statement: Not applicable.

Acknowledgments: The authors of the present paper would like to sincerely thank Marek Halama, Regional Sales Manager of Construction Commercial Department from Thyssenkrupp Materials Poland S.A. for disclosure of technical information and sharing of information concerning cellular polycarbonate sheets, as well as for help in obtaining a cellular sheet for research, and Waldemar Strzelczyk, Wiga s.c., Szczecin for free of charge release of a polycarbonate sheet for experimental investigations.

Conflicts of Interest: The authors declare no conflict of interest. The funders had no role in the design of the study; in the collection, analyses, or interpretation of data; in the writing of the manuscript, or in the decision to publish the results.

\section{Appendix A}

Figure A1 presents research results for a sunny day, Figure A2 refers to a cloudy day, and Figure A3 shows research results for a day with diversified cloudiness. It is quite obvious that for each day of the year, including days chosen for research, irrespective of weather, the distribution of irradiance $G_{0}$ in the day period has a symmetrical and regular run (Figures A1a, A2a and A3a), because irradiance $G_{0}$ is calculated from Formula (3). If the day is sunny, irradiances $G_{1}$ and $G_{2}$ have similar runs (Figure A1a). Maximal values of irradiances are located near midday. Values of parameters TST and K, calculated from 
irradiance as a function of time, are given in Figure A2b. On a sunny day, both parameters achieve maximal values in hours near midday. In the case of parameter TST, two local maximal values are to be observed, in the beginning and at the end of daytime. It should be supposed that maximal values of TST in the morning and in the evening result from the dominance of diffusive radiation in global radiation in these daytimes. Analysis of typical meteorological and statistical climatic data for the area of Poland (for the city of Szczecin) [33] shows that only diffusive radiation occurs in early morning and late evening hours. Figure A4 shows the share of diffusive radiation in the total radiation in successive hours of individual statistical days in August. Similar changes of TST were also stated by Čekon and Slávik [25]. Figure A1c shows changes of TST as a function of K. For a sunny day, more points at Figure A1c are located on the right part of the diagram $(K>0.5)$.

When the day is cloudy, the runs of irradiances $G_{1}$ and $G_{2}$ do not have regular shapes (Figure A2a). The values of irradiances $G_{1}$ and $G_{2}$ are significantly lower than the value of irradiance $G_{0}$. Values of parameter TST are approximately equal to 0.7 (Figure A2b). Relatively small TST changes on cloudy days are caused by the dominance of diffused radiation in global radiation. Values of parameter K are smaller than 0.5 (Figure A2b), and points TST $=f(K)$ are located on the left side of the diagram.

When the day is cloudy, the runs of irradiances $G_{1}$ and $G_{2}$ do not have regular shapes (Figure A2a). The values of irradiances $G_{1}$ and $G_{2}$ are significantly lower than the value corresponding to irradiance $G_{0}$. Values of parameter TST are approximately equal to 0.7 (Figure A2b). The relatively small TST changes on cloudy days are caused by the dominance of diffused radiation in global radiation. Values of parameter $\mathrm{K}$ are smaller than 0.5 (Figure A2b), and points TST $=\mathrm{f}(\mathrm{K})$ are located on the left side of the diagram $(\mathrm{K}<0.5)$.

The changes of parameter K shown in Figures A1b, A2b and A3b show only the degree of cloudiness that occurs at a given time of day. Of course, the runs of $K$ are similar to runs of irradiances $G_{1}$ and $G_{2}$ on the analysed days.

Changes of TST as a function of parameter $\mathrm{K}$ are only of qualitative character (Figures A1c, A2c and A3c). Similarly, transmittance values equal or higher than the unit were neglected, because such values are physically impossible. They confirm the data obtained from the analysis of previously discussed figures. Locations of points on the runs describe the character of cloudiness that prevailed on a given day. 
a)

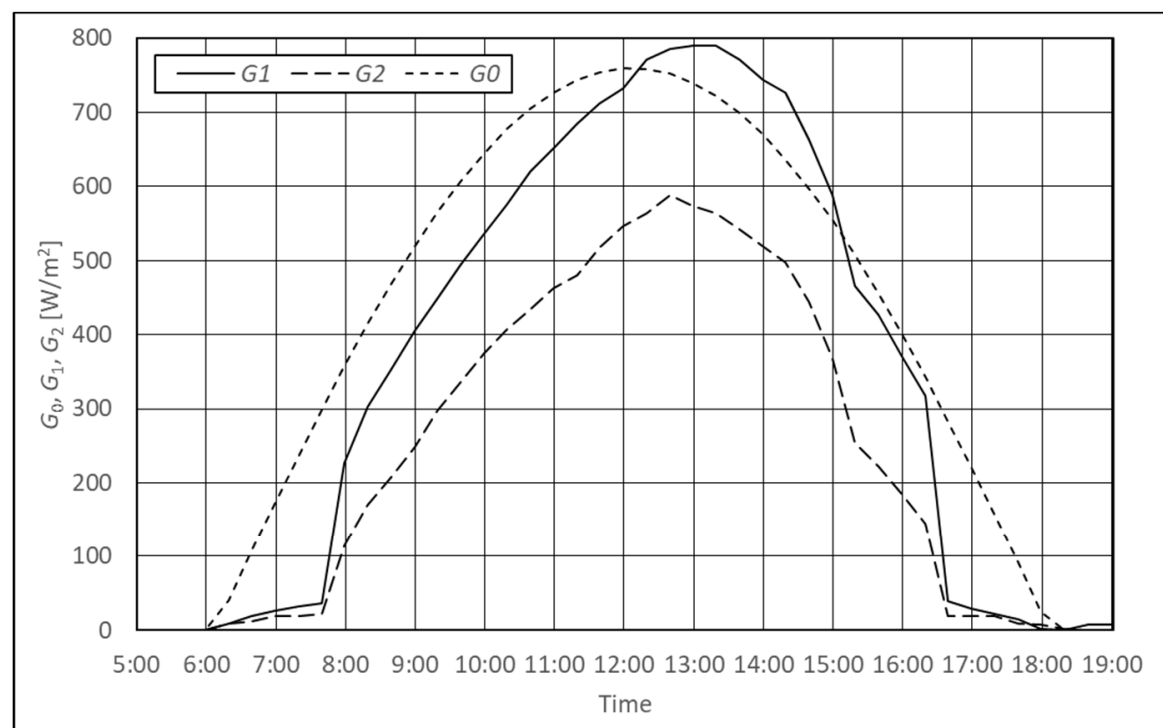

b)
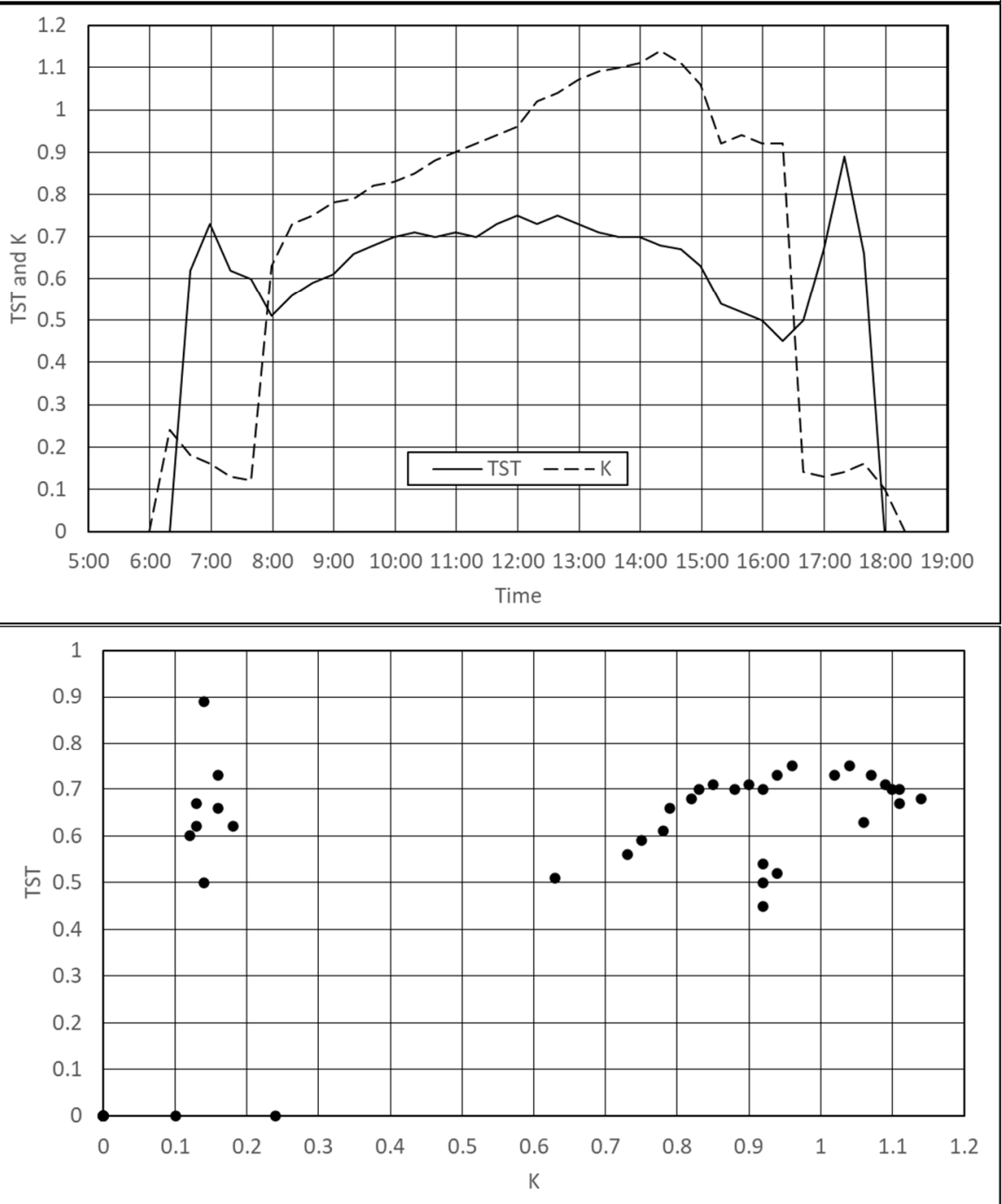

Figure A1. Results for sunny day-6 August 2020; (a) irradiance outside of earth's atmosphere as well as above and beneath a polycarbonate sheet as a function of time, (b) TST and K parameters as a function of time. (c) Parameter TST as a function of parameter K. 
a)

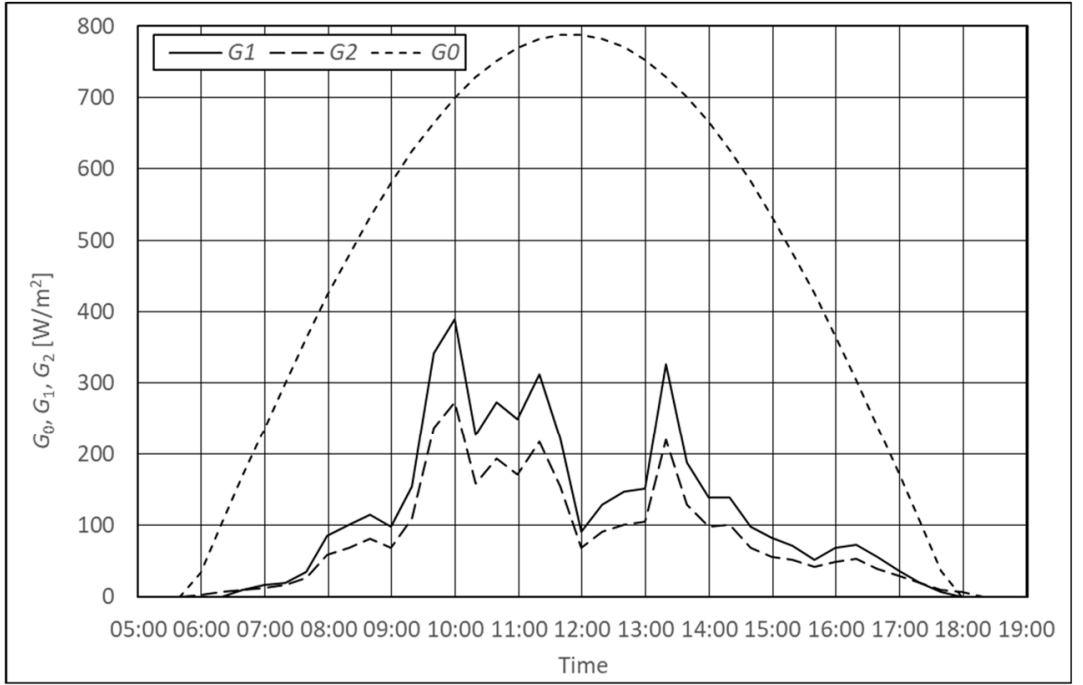

b)

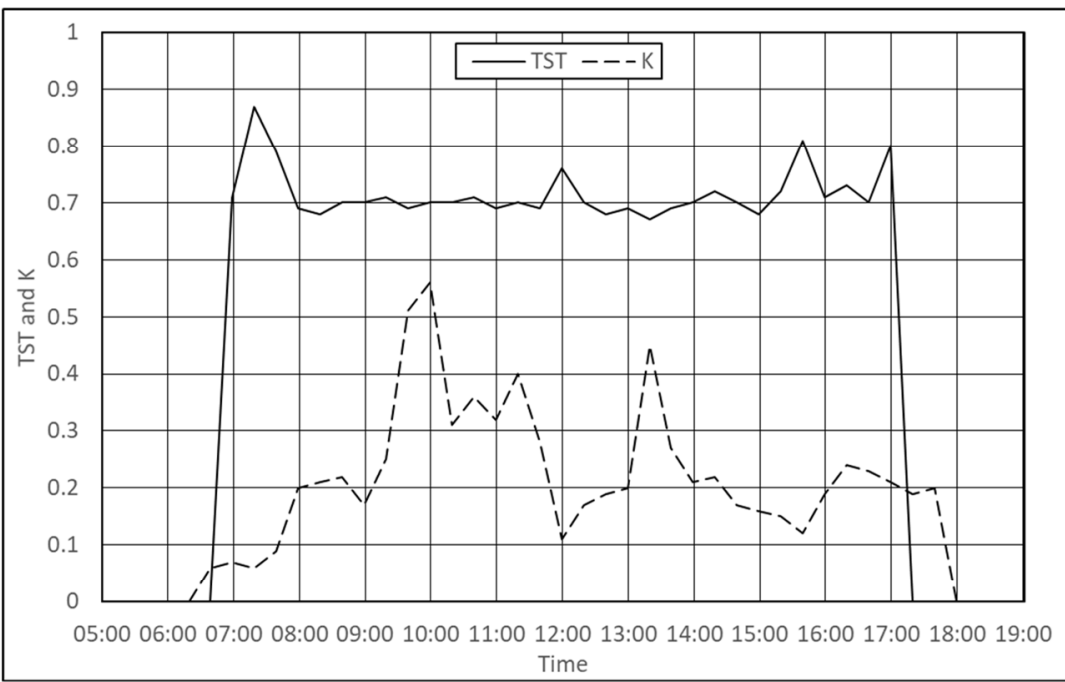

c)

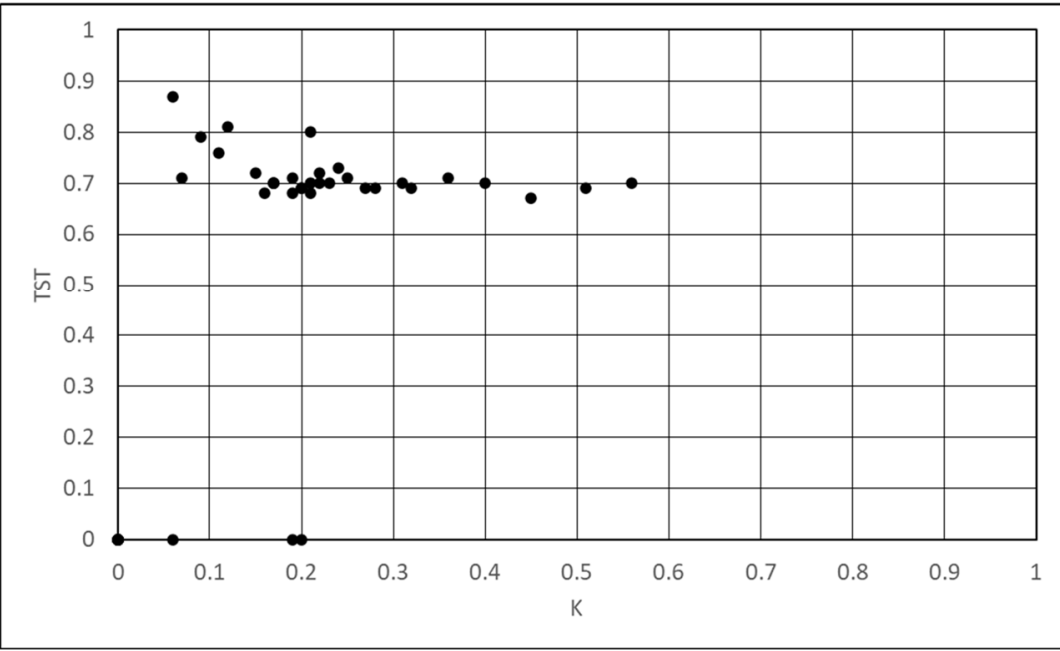

Figure A2. Results for cloudy day-28 August 2020 (a) irradiance outside of earth's atmosphere as well as above and beneath a polycarbonate sheet as a function of time, (b) Changes of TST and K parameters as a function of time (c) Parameter TST as a function of parameter K. 
a)

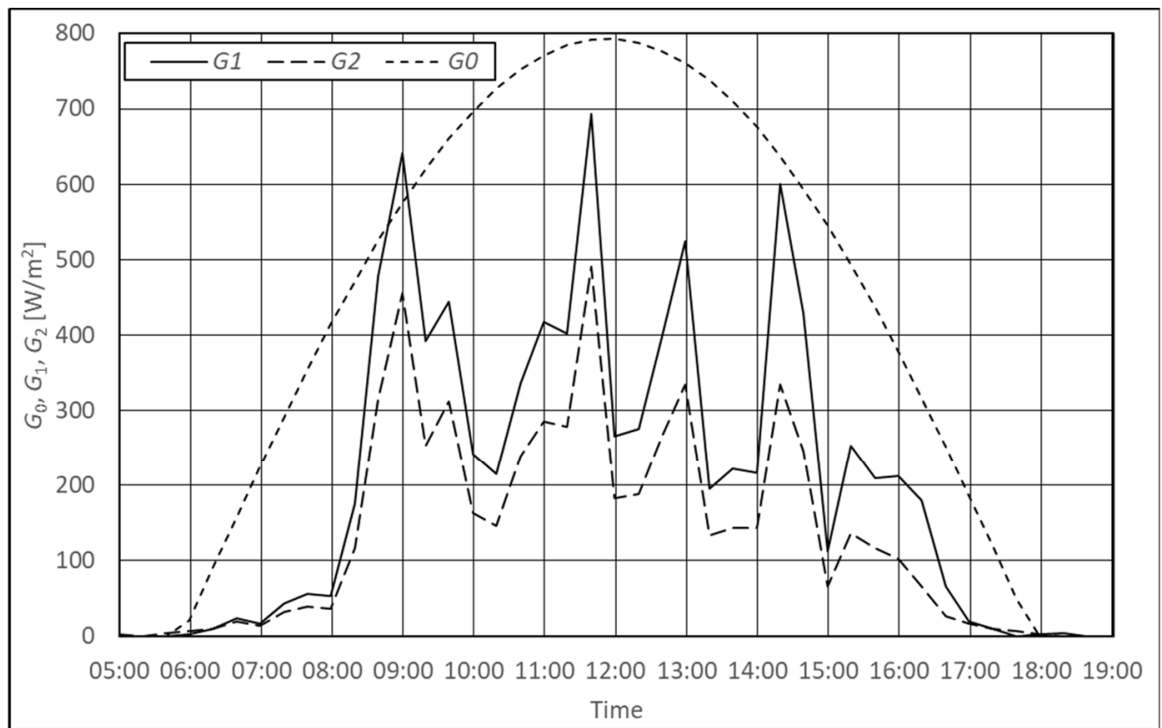

b)

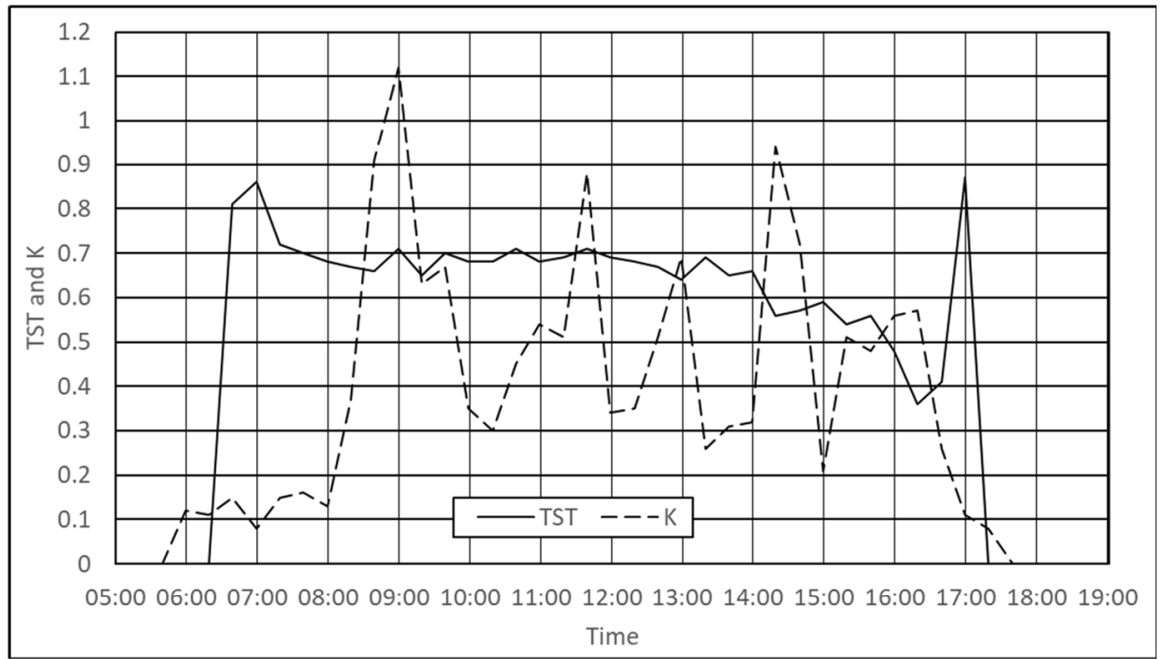

c)

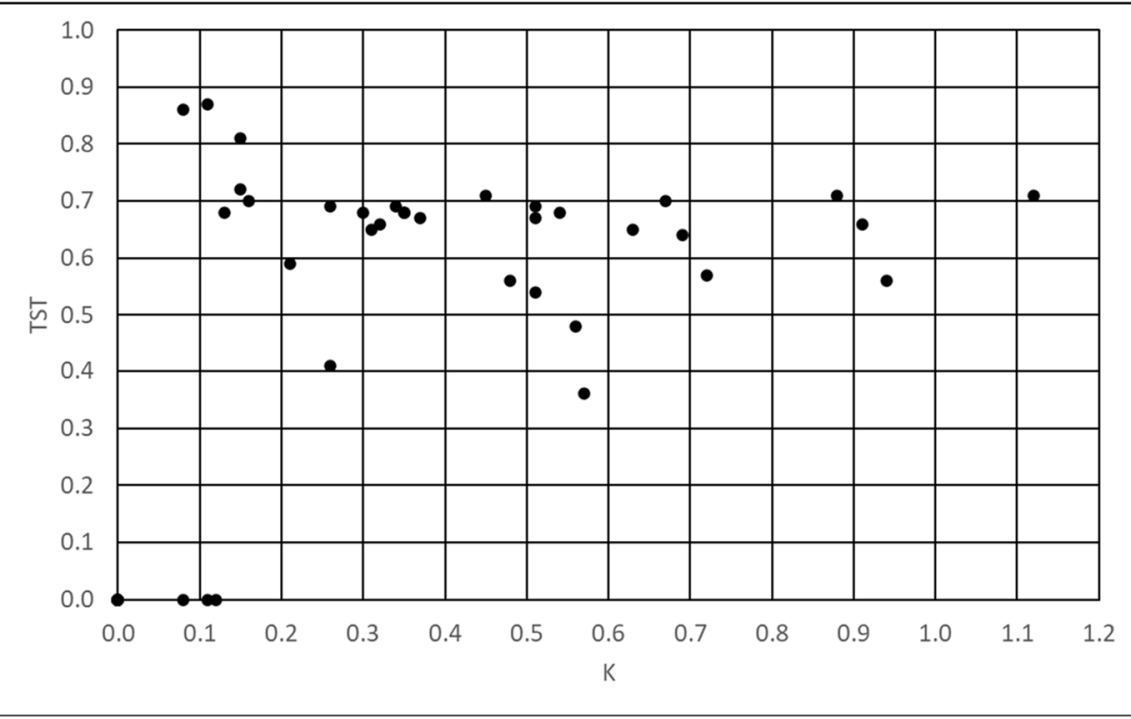

Figure A3. Results for a day with diversified cloudiness-31 August 2020; (a) irradiance outside of earth's atmosphere as well as above and beneath a polycarbonate sheet as a function of time, (b) TST and $\mathrm{K}$ parameters as a function of time, (c) Parameter TST as a function of parameter K. 


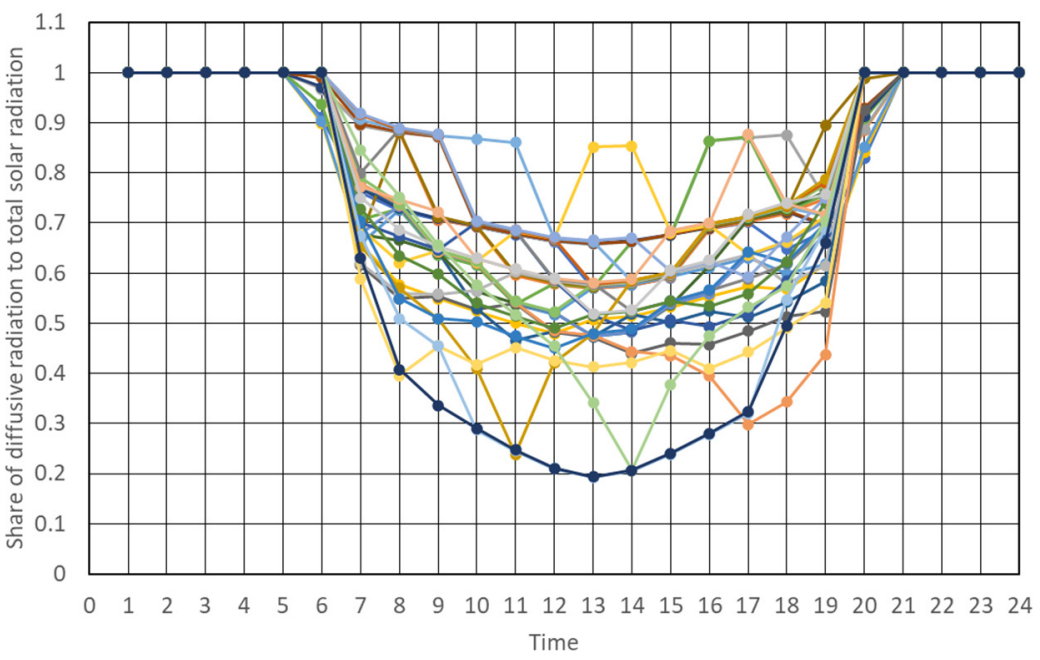

Figure A4. Share of diffusive radiation to total solar radiation as a function of time in August 2020.

\section{References}

1. Kerra, N.; Gouldson, A.; Barrett, J. The rationale for energy efficiency policy: Assessing the recognition of the multiple benefits of energy efficiency retrofit policy. Energy Policy 2017, 106, 212-221. [CrossRef]

2. Pérez-Lombard, L.; Pout, C. A review on buildings energy consumption information. Energy Build. 2008, 40, 394-398. [CrossRef]

3. Karlsson, J.; Roos, A. Modelling the angular behaviour of the total solar energy transmittance of windows. Sol. Energy 2000, 69, 321-329. [CrossRef]

4. Karlsson, J.; Rubin, M.; Ross, A. Evaluation of predictive models for the angle-dependent total solar energy transmittance of glazing materials. Sol. Energy 2001, 71, 23-31. [CrossRef]

5. Song, S.; Haberl, J.S. Simplified field measurement and verification of global solar transmittance for glazing samples under natural clear-sky conditions. Sol. Energy 2017, 155, 706-714. [CrossRef]

6. Kralj, A.; Dreva, M.; Žnidaršic, M.; Cerne, B.; Hafner, J.; Jelle, B.P. Investigations of 6-pane glazing. Properties and possibilities. Energy Build. 2019, 190, 61-68. [CrossRef]

7. Manz, H. Total solar energy transmittance of glass double façades with free convection. Energy Build. 2004, 36, 127-136. [CrossRef]

8. Simmler, H.; Binder, B. Experimental and numerical determination of the total solar energy transmittance of glazing with venetian blind shading. Build. Environ. 2008, 43, 197-204. [CrossRef]

9. Morreti, E.; Belloni, E.; Merli, F.; Zinazi, M.; Buratti, C. Laboratory and pilot scale characterization of granular aerogel glazing systems. Energy Build. 2019, 202, 109349. [CrossRef]

10. Ghosh, A.; Norton, B.; Mallick, T.K. Influence of atmospheric clearness on PDLC switchable glazing transmission. Energy Build. 2018, 172, 257-264. [CrossRef]

11. Dawson, M.; Harrison, D.; Craig, S.; Gill, Z. Improving the thermal performance of single-glazed windows using translucent granular aerogel. Int. J. Sustain. Eng. 2011, 4, 266-280. [CrossRef]

12. A Complete Guide to Polycarbonate (PC). Available online: https://omnexus.specialchem.com/selection-guide/polycarbonatepc-plastic (accessed on 14 April 2021).

13. Lexan Thermoclear Sheet. Available online: https://sfs.sabic.eu (accessed on 15 April 2021).

14. Multi-Wall Polycarbonate Sheets. Available online: https://ugplast-inc.com (accessed on 16 April 2021).

15. Products, Polycarbonate. Available online: https://www.edplastics.co.uk (accessed on 16 April 2021).

16. Polycarbonate Multiwall. Available online: https://www.arlaplast.com (accessed on 16 April 2021).

17. Polycarbonate Panel Systems between Roof Sandwich Panel. Available online: https://www.polinetlux.com (accessed on 16 April 2021).

18. Tantau, H.-J.; Hinken, J.; Solar, B.; Max, J.F.J.; Ulbrich, A.; Schurr, U. Transmittance of greenhouse covering materials solar transmittance of greenhouse covering materials. Acta Hortic. 2012, 956, 441-448. Available online: https:/ / www.researchgate. net/publication/284250575_Solar_transmittance_of_greenhouse_covering_materials (accessed on 31 December 2021). [CrossRef]

19. Technical; Multiwall PC Sheets. Available online: https://www.epse.org (accessed on 16 April 2021).

20. Krajewski, B. Poliwęglany (Polycarbonate); WNT: Warszawa, Poland, 1971. (In Polish)

21. Zapałowicz, Z.; Garnysz-Rachtan, A. Estimation of transmission of solar radiation for polycarbonate retractable swimming pool enclosures. Arch Thermodyn. 2021, 42, 129-146. [CrossRef]

22. EN 16153:2013+A1:2015; Light Transmitting Flat Multiwall Polycarbonate (PC) sheets for Internal and External Use in Roofs, Walls and Ceilings. Requirements and Test Methods. British Standards Institution: London, UK, 2015. 
23. Garnysz, A.; Zapałowicz, Z. Model of heat and mass transfer in swimming pools with roofing systems. In Developments in Mechanical Engineering; Cieśliński, J.T., Szymczyk, J., Eds.; Gdańsk University of Technology Publishers: Gdańsk, Poland, 2012; Volume 5, pp. 49-58.

24. Garnysz, A.; Zapałowicz, Z. Comparison of characteristic thermal parameters for a swimming pool with retractable pool enclosures exploited in autumn and spring seasons. In Proceedings of the XVth International Conference on Heat Transfer and Renewable Sources of Energy, Międzyzdroje, Poland, 10-13 September 2014; Stachel, A.A., Mikielewicz, D., Eds.; Wydawnictwo Uczelniane ZUT w Szczecinie: Szczecin, Poland, 2014; pp. 301-306.

25. Čekon, M. Optical Performance of Polycarbonate Multi-Wall Panels in the Form of Transparent Insulation Based on Long-Term Outdoor Measurements. Available online: https:/ / www.researchgate.net/publication/328465260 (accessed on 2 September 2020). [CrossRef]

26. Čekon, M.; Slávik, R. Total solar transmittance quantifying of transparent insulation building materials based on real climate outdoor measurements. Energy Procedia 2017, 132, 243-248, Peer-review under responsibility of the organizing committee of the 11th Nordic Symposium on Building Physics. [CrossRef]

27. Čekon, M.; Struhala, K. Polycarbonate multi-wall panels integrated in multi-layer solar façade concepts. In Proceedings of the IOP Conference Series: Materials Science and Engineering, Bangkok, Thailand, 24-26 February 2018; Volume 415, p. 012019. [CrossRef]

28. Technical Approval (Aprobata Techniczna) ITB AT-15-8917/2012. Ptyty Komorowe z Poliwęglanu Lexan Thermoclear LT2UV: 62RS, 82 RS, 102 RS, 105 RS, 163TS, 166RS, 165X, 169X, 206RS, 205X, 209X, 256RS, 255X, 259X, 253X i 325X; Technical Approval: Warszawa, Poland, 2013; ISBN 978-83-249-6235-8. (In Polish)

29. Sabic. Glazing installation guide. In Un Coated and Coated Solid Lexan Sheet; Sabic: Riyadh, Saudi Arabia, 2015; Available online: https:/ / www.sabic.com/sfs (accessed on 16 April 2021).

30. Kipp \& Zonen. Instruction Manual Pyranometr/Albedometer CMP11/CMP14, 2000, CMP11 Secondary Standard Pyranometer; Kipp \& Zonen: Delft, The Netherlands, 2000; Available online: Kippzonen.com (accessed on 3 January 2021).

31. Pluta, Z. Podstawy Teoretyczne Fototermicznej Konwersji Energii Słonecznej (Theoretical Basis of Photothermal Solar Energy Conversion); Oficyna Wydawnicza Politechniki Warszawskiej: Warszawa, Poland, 2006; ISBN 83-7207-229-9. (In Polish)

32. Wojnicki, O. Oszacowanie Współczynnika Transmisyjności Poliwęglanowej Komorowej Osłony Basenowej dla Promieniowania Słonecznego (Evaluation of Solar Transmittance for Polycarbonate Sheet of Swimming Pool Enclosure). Diploma Thesis, West Pomeranian University of Technology, Szczecin, Poland, 2021. (In Polish).

33. Otwarte Dane. Typowe lata meteorologiczne i statystyczne dane klimatyczne dla obszaru Polski do obliczeń energetycznych budynków (Typical meteorological years and climatic data for Poland used to energetical calculation of buildings). In Typowe Lata Meteorologiczne i Statystyczne Dane Klimatyczne dla Obszaru POLSKI do Obliczeń Energetycznych Budynków; Otwarte Dane: Warszawa, Poland, 2019. (In Polish) 